\title{
Teaching Quality Evaluation of a New University Mathematics Teaching Mode-an Empirical Research
}

\author{
Ya Tian ${ }^{1, a}$, Peng Yang ${ }^{1, a}$, Na Zhang ${ }^{2, a}$, Guorui Yang ${ }^{3, b}$ \\ ${ }^{1}$ Department of Mathematics, Xingtai University, Xingtai, 054001, China \\ ${ }^{2}$ Xingtai Medical College, Xingtai, 054000, China \\ ${ }^{3}$ The Second Middle School of Xingtai, xingtai, 054001, China \\ ae-mail: tianya_04@126.com, be-mail: 1068686@126.com
}

\begin{abstract}
Keywords: teaching reform; mathematics experiments; the analytic hierarchy process; teaching mode
\end{abstract}

\begin{abstract}
Under the background of mathematics education reform, we put a new teaching mode into practice-the teaching mode of university mathematics integrated into mathematics experiment. And we devote ourselves to the research on the teaching quality evaluation of the new teaching mode. Using analytic hierarchy process (AHP) combined with questionnaire survey statistics data, we study quantitatively the teaching quality of the new mathematics teaching mode and the traditional mathematics teaching mode. We establish a mathematical model and calculate by using the mathematics software MATLAB. Finally we get that the new mathematics teaching mode is superior to the traditional mathematics teaching mode and we give some suggestions on the implementation of the new teaching mode.
\end{abstract}

\section{Introduction}

In 1988, Rossciacr Institute of Technology in the United States formally led the mathematical experiments into mathematics classes. And in 1997, the University of Science and Technology of China carried out the mathematics experiment teaching for the first time. Then many mathematics researchers and workers gradually added the mathematics experiment into the university mathematics teaching, and added the experiments teaching part. So the university mathematics teaching reform was greatly promoted.

In the mathematics experiment teaching part, learners can compile program to calculate, make symbolic computation and draw figure by using computer. Learners can make mathematical discovery and find the experimental laws from the experimental observation. Learners can make case analysis and simulation to acquire the knowledge and information which cannot be obtained in the traditional mathematics learning.

Nowadays, mathematics learning is not only simple computation and deduction but technique which can be used in various fields. Mathematics learning must be combined with the mathematics software. Learners should be able to express problems with mathematics language and solve the problems efficiently by using computer. Accordingly the learners can improve their ability of understanding the world quantitatively and improve their research ability. Thus the teaching mode of university mathematics integrated into mathematics experiments is valuable. Therefore it is a research hotspot.

Based on the teaching practice of the mathematics experiment integrating into university mathematics, we explore quantitatively the teaching quality of the new teaching method and traditional teaching mode through the investigation and analysis, using AHP to establish the mathematical model.

\section{Exploration of a New Teaching Mode of University Mathematics}

In recent years, we devoted ourselves to the exploration of university mathematics teaching mode in university integrated into the mathematics experiment, and in 2009, we began to put the new teaching mode into practice [1].We divided university mathematics teaching into theory module and experiment module. In theory teaching module, the Advanced Mathematics, Linear Algebra, Probability and Statistics were all integrated into the mathematics experiment contents. 
The experiment module was based on the theory module of the university mathematics. According to the corresponding teaching contents, we taught the MATLAB and MATHEMATICA software and so on. We gave students demonstration and explanation, and then put forward some problems, let students compile programs to explore the conclusion, and thus deepened the understanding of the theories.

For example, in the Linear Algebra teaching process, the experiment teaching part mainly include contents such as determinant calculation, matrix calculation, solving the linear equations, solving the Eigen value and eigenvector of matrix.

In the advanced mathematics teaching process, the main contents of the experiment teaching part is drawing the basic elementary functions' graphics, calculating limits, derivatives, integrals and series, drawing graphics of two variables function, computing the partial derivatives and the double integrals etc..

\section{Evaluation of the New Teaching Mode of the university mathematics}

Through questionnaire survey and data handling, using analytic hierarchy process (AHP), we got quantitative evaluation on the teaching quality of the new teaching mode and traditional teaching mode. Accordingly we got the teaching effect difference. See figure 1 for the evaluation index system.

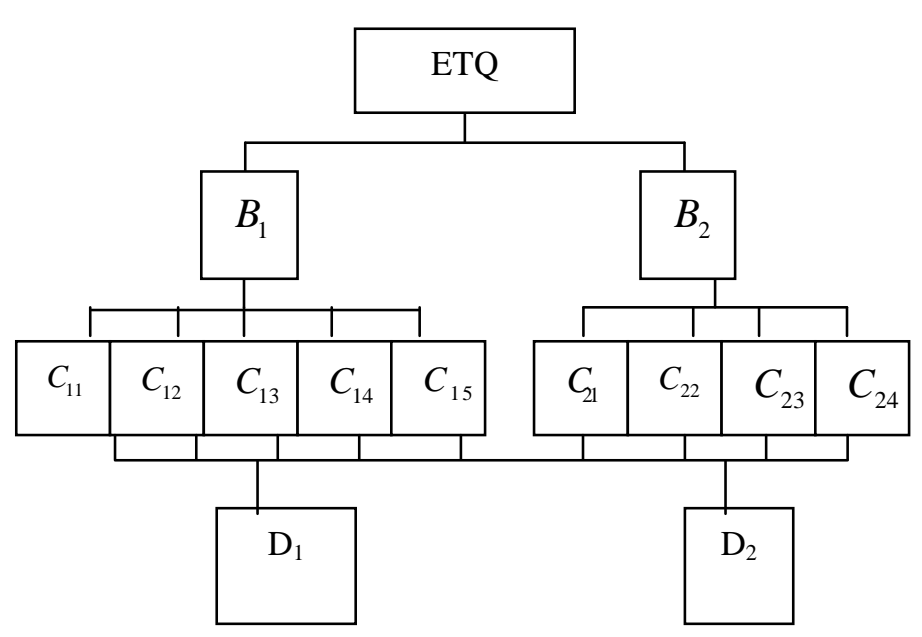

Figure1. Evaluation Index System

TABLE1. INDEX RATIO SCALE

\begin{tabular}{|c|c|c|}
\hline$I_{k}$ & $a(X, Y)$ & explanation (to the upper level) \\
\hline$I_{-4}$ & $9^{-\frac{9}{9}}$ & $\begin{array}{c}\text { Element } \mathrm{Y} \text { is extremely } \\
\text { important than element } \mathrm{X}\end{array}$ \\
\hline$I_{-3}$ & $9^{-\frac{6}{9}}$ & $\begin{array}{l}\text { Element Y is strongly important } \\
\text { than element } \mathrm{X}\end{array}$ \\
\hline$I_{-2}$ & $9^{-\frac{3}{9}}$ & $\begin{array}{l}\text { Element } \mathrm{Y} \text { is obviously } \\
\text { important than element } \mathrm{X}\end{array}$ \\
\hline$I_{-1}$ & $9^{-\frac{1}{9}}$ & $\begin{array}{l}\text { Element } \mathrm{Y} \text { is slightly important } \\
\text { than element } \mathrm{X}\end{array}$ \\
\hline$I_{0}$ & $9^{0}$ & $\begin{array}{l}\text { Element } \mathrm{Y} \text { is equally important } \\
\text { than element } \mathrm{X}\end{array}$ \\
\hline$I_{1}$ & $9^{\frac{1}{9}}$ & $\begin{array}{l}\text { Element } \mathrm{X} \text { is slightly important } \\
\text { than element Y }\end{array}$ \\
\hline$I_{2}$ & $9^{\frac{3}{9}}$ & $\begin{array}{l}\text { Element } \mathrm{X} \text { is obviously } \\
\text { important than element } \mathrm{Y}\end{array}$ \\
\hline$I_{3}$ & $9^{\frac{6}{9}}$ & $\begin{array}{l}\text { Element } \mathrm{X} \text { is strongly important } \\
\text { than element } \mathrm{Y}\end{array}$ \\
\hline$I_{4}$ & $9^{\frac{9}{9}}$ & $\begin{array}{l}\text { Element } \mathrm{X} \text { is extremely } \\
\text { important than element } \mathrm{Y}\end{array}$ \\
\hline & \multicolumn{2}{|c|}{$9^{\frac{k}{9}}(k=-9,-6,-3,-1,0,1,3,6,9)$} \\
\hline
\end{tabular}

ETQ: The evaluation of teaching quality

$\mathrm{B}_{2}$ : Teaching effect

$\mathrm{C}_{12}$ : Innovation consciousness training

$\mathrm{C}_{14}$ : Learning interest

$\mathrm{C}_{21}$ : Grasp basic knowledge problem

$\mathrm{C}_{23}$ : Mathematical technical ability ability

D1: The traditional teaching mode

$\mathrm{B}_{1}$ : Teaching method

$\mathrm{C}_{11}$ : The teaching content abundance

$\mathrm{C}_{13}$ : Students inspiration and participation

$\mathrm{C}_{15}$ : Highlight the key points

$\mathrm{C}_{22}$ : skills of analyzing and solving

$\mathrm{C}_{24}$ : The cultivation of comprehensive

D2: The new teaching mode 


\section{(1)Comparison matrix, index weight and consistency check matrix in the evaluation system}

The index weight react the important role in the evaluation system. Determining the index weight is the key work in the teaching quality evaluation. We use the analytic hierarchy process (AHP) to compare the importance of the elements in the same layer with regard to the upper layer, construct the comparison judgment matrix, and solve the largest Eigen value and the corresponding eigenvectors of the judgment matrix. At last, we obtain the index weight.

Step1: To establish the comparison judgment matrix

Let the students of our university give the relative materiality of each hierarchy elements in the evaluation system. We use the exponential scale method [2] to give the scale value $a(X, Y)$ of the relative importance of the variable $I_{k}$. The scale value see table 1 .

Let $S=\left\{S_{1}, S_{2}, \cdots, S_{n}\right\}$ be the students set, $n$ is the number of participants in the survey, and let $X=\left\{X_{1}, X_{2}, \cdots, X_{k}\right\}(k \geq 2)$ be the same layer element set. In order to simplify the questionnaire, we select a reference element $X_{i_{0}}$. The degree of the remaining elements' importance is ascertained by students' vote. The two elements' relative importance of scale $a\left(X_{i}, X_{j}\right)$ is calculated by the vector $I=\left(I_{-4}, I_{-3}, \cdots, I_{4}\right)$, which is the result of each element's votes. We call $c=\left(c_{-4}, c_{-3}, \cdots, c_{4}\right)=(-9,-6,-3,-1,0,1,3,6,9)$, the relevant vector which represents the important degree. The vote result of the relative importance of vector is represented by $b_{i}$, that is $b_{i}=\left(b_{i,-4}, b_{i,-3}, \cdots, b_{i}, 4\right)$.

See table 2 for the relevance vector $X_{i}, X_{j}$ and $X_{i_{0}}$ which represents the important degree.

TABLE2. THE NUMBER OF VOTES

\begin{tabular}{|c|c|c|c|c|c|c|c|c|c|}
\hline & $I_{-4}$ & $I_{-3}$ & $I_{-2}$ & $I_{-1}$ & $I_{0}$ & $I_{1}$ & $I_{2}$ & $I_{3}$ & $I_{4}$ \\
\hline$X_{i}$ & $b_{-4 i}$ & $b_{-3 i}$ & $b_{-2 i}$ & $b_{-1 i}$ & $b_{0 i}$ & $b_{1 i}$ & $b_{2 i}$ & $b_{3 i}$ & $b_{4 i}$ \\
\hline$X_{j}$ & $b_{-4 j}$ & $b_{-3 j}$ & $b_{-2 j}$ & $b_{-1 j}$ & $b_{0 j}$ & $b_{1 j}$ & $b_{2 j}$ & $b_{3 j}$ & $b_{4 j}$ \\
\hline
\end{tabular}

Using the following formula, we obtain that: $a\left(X_{i}, X_{j}\right)=\left\{\begin{array}{l}9^{\operatorname{dot}\left(c, b_{i}\right) /\left(9 \operatorname{sum}\left(b_{i}\right)\right)}, j=i_{0}, i \neq i_{0} \\ 9^{\operatorname{dot}\left(c,\left(b_{i}-b_{j}\right)\right)\left(9 \operatorname{sum}\left(\left(a b s\left(b_{i}-b_{j}\right)\right)\right)\right.}, i \neq i_{0}, j \neq i_{0}, i \neq j, b_{i} \neq b_{j} \\ 1, i=j \text { 或 } b_{i}=b_{j}\end{array}\right.$

Here $\operatorname{sum}\left(b_{i}\right)$ expresses summation of the elements of the vector $b_{i} \cdot \operatorname{dot}\left(c, b_{i}\right)$ shows the dot product of the vector $c$ and $b_{i}$. The comparison judgment matrix $R(A, X)$ of the Element $X$ layer according to the upper element $A$ is $R(A, X)=\left(a\left(X_{i}, X_{j}\right)\right)_{k \times k}$.

Step2: The weight and the consistency test.

In the process of constructing judgment matrix, experts and students will produce biased in sorting the measure index importance. Therefore, we need to check the consistency of judgment matrix. We mainly explore the following index:

Coincidence index $C I=\frac{\lambda_{\max }-n}{n-1}$. Where $\lambda_{\max }$ is the largest Eigen value of the judgment matrix, and $n$ is the order of the judgment matrix.

Random Consistency Index:

The Random consistency index $R I$ is given by the actual experience. We give the index in table 3. 
TABLE3. THE RANDOM CONSISTENCY RI

\begin{tabular}{|c|c|r|r|r|c|}
\hline $\mathrm{n}$ & 1 & 2 & 3 & \multicolumn{1}{c|}{4} & 5 \\
\hline$R I$ & 0 & 0 & 0.58 & 0.9 & 1.12 \\
\hline $\mathrm{n}$ & 6 & 7 & 8 & 9 & 10 \\
\hline$R I$ & 1.24 & 1.32 & 1.41 & 1.45 & 1.49 \\
\hline
\end{tabular}

The consistency ratio index $C R=\frac{C I}{R I}$.

If $C R<0.1$, we deem that the consistency of the judgment matrix is acceptable, and the corresponding feature vector can be used as ranking weight column vector.

Step3: The combined weight and the combined consistency test.

Combined weight vector:

Let the first $n_{k-1}$ element's sorting weight vector of the first $k-1$ layer is $w^{(k-1)}=\left(w_{1}^{k-1}, w_{2}^{k-1}, \cdots, w_{n_{k-1}}^{k-1}\right)^{T}$.

And let the $n_{k}$ element's weight vector of the $k$ layer relative to the first $\mathrm{j}$ element of the upper layer is $P_{j}^{(k)}=\left(p_{1 j}^{(k)}, p_{2 j}^{(k)}, \cdots, p_{n_{k} j}^{(k)}\right)^{T}$.The first $k$ layer's sorting weight matrix relative to the first $k-1$ layer is

$P^{(k)}=\left[P_{1}^{(k)}, P_{2}^{(k)}, \cdots, P_{n_{k-1}}^{(k)}\right]_{n_{k} \times n_{k-1}}$.The first $n_{k}$ element's sorting weight vector of the first $k$ layer relative to the target layer is $w^{(k)}=P^{(k)} w^{(k-1)}=P^{(k)} P^{(k-1)} P^{(k-2)} \cdots P^{(3)} w^{(2)}(k>2)$.

Combined consistency test:

Let the consistency index vector of the first $k$ layer is $C I^{(k)}=\left(C I_{1}^{(k)}, C I_{2}{ }^{(k)}, \cdots, C I_{n_{k-1}}{ }^{(k)}\right)$. And the random consistency index vector of the $k$ layer is $R I^{(k)}=\left(R I_{1}^{(k)}, R I_{2}{ }^{(k)}, \cdots, R I_{n_{k-1}}{ }^{(k)}\right)$. The combined consistency index $Z C I^{(k)}$ of the first $k$ layer relative to the target layer is $Z C I^{(k)}=C I^{(k)} w^{(k-1)}$. The combined random consistency index $Z R I^{(k)}$ of the first $k$ layer relative to the target layer is $Z R I^{(k)}=R I^{(k)} w^{(k-1)}$. The combined consistency ratio is $C R^{(k)}=C R^{(k-1)}+\frac{Z C I^{(k)}}{Z R I^{(k)}}(k>2)$.

If $C R^{(k)}<0.1$, it is assumed that the level of judgment matrix is agreed by the consistency test.

\section{(2)Expert evaluation about mathematics experiments teaching and questionnaire design as well as statistical results.}

In order to get the combination weights of the lowest elements in the evaluation system, meantime to reduce the workload and statistics to fill in a form, the questionnaire survey was carried out according to the following table. Number of people participating in the questionnaire survey is forty-nine. When we finish the statistical treatment of the questionnaire data, we use the mathematical model described above to calculate with MATLAB program. From the calculation results we can see that in the evaluation of teaching mode mathematics experiments teaching account for 0.5278 , while the traditional teaching model account for 0.4722 . Therefore in the evaluation of teaching mode, mathematics experiment teaching mode is superior to the traditional teaching mode. This result is consistent with actual experience.

It should be pointed out that: this model uses index method when we establish the judgment matrix, but the random consistency index refers to the "1-9 scale law" [3] which Saaty suggests. This reduces the reliability of the results. So if you want to get a more objective evaluation results, we can calculate random consistency again with the method which Saaty establish RI. 


\section{Conclusion}

In the evaluation of the teaching mode, we use the analytic hierarchy process to establish the mathematical model, and quantitatively analyse the qualitative questions. We can receive the evaluation results more objectively, reduce the subjective judgment to some extent and make the results more reliable. We can conclude that the teaching mode of university mathematics integrated into mathematics experiment is better than the traditional teaching mode from the calculation results.

Judging from the current situation, there still exist some problems following in carrying out the teaching mode in a wide range.

(1)For the traditional teaching, some people think that mathematics experiment takes too much time to complete the teaching plan. In fact, mathematics experiment in university mathematics teaching not only lies in the search for mathematical knowledge itself, but also in the application of mathematical knowledge. It is an attempt to reform mathematical system, content and method. This is beneficial to the cultivation of the initiative, creativity and team spirit of students, to improve students' overall qualities. Mathematics teaching mode adding to experiment is not to replace other teaching mode, but is a good supplement to the traditional teaching mode. Mathematical experiment study which can be applied for a long time is in accordance with the requirements of quality education.

(2) In the conventional mathematics teaching, teachers who develop mathematics experiment face many challenges from professional quality aspects. On the one hand, we must study and improve the knowledge on computer, because more and more computer knowledge will be used in the mathematics experiment, even to use the knowledge on simple program sometimes. On the other hand, teachers should have extensive mathematical knowledge and stronger research ability in accordance with the quality requirements of teachers.

\section{References}

[1] M.L.Wang. Application of Mathematical Experiment in Mathematical Teaching of University[J], Studies in College Mathematics, Vol.12, No.3,2009.

[2] Y.j. Lv, W.Zhang. Kernel Function of Index Scale in AHP Scale System[J], Journal of Systems Engineering, Vol.18, No.5, 2003.

[3] Y. Liu, J. Wu. Some Problems in the Application of the Hierarchical Analysis Method[J], Journal of Wenzhou University, 2002.12 (4)

[4] Z.Q. Luo, S.L. Yang. Comparative Study on Several Scales in AHP[J], Systems Engineeringtheory \& Practice, 2004.9.

[5] Z.H. Yang, T.N. Chen, L.Z. Liu. Fuzzy-optimization Model Based on Improved Analytic Hierarchy Process[J], Mathematics in Practice and Theory, Vol.40,No.10, 2010. 